\title{
Pulmonary regurgitation in transposition of the great arteries
}

\author{
SHAKEEL AHMED QURESHI, JOSE A ETTEDGUI, OWEN D H JONES \\ From the Department of Paediatric Cardiology, Guy's Hospital, London
}

SUMMARY A female infant who presented with cyanosis and tachypnoea was found to have transposition of the great arteries, a ductus arteriosus, and a ventricular septal defect. An aortogram showed evidence of mild pulmonary regurgitation, which persisted after a Senning's operation; this is a hitherto unrecognised clinical finding.

Pulmonary regurgitation is not a recognised preoperative finding in transposition of the great arteries and it may not be of any importance when the definitive surgery entails venous redirection. When an arterial switch operation is contemplated, however, pulmonary regurgitation may become an important consideration because the pulmonary valve then functions as the aortic valve and its competence may be important in long term outcome.

This report shows that pulmonary valve regurgitation may be present in some patients from early infancy. This may influence the type of operation that is performed.

\section{Case report}

A female infant presented at the age of five weeks with increasing cyanosis and tachypnoea. There was a grade $2 / 6$ pansystolic murmur at the lower left sternal edge and a continuous murmur at the second left intercostal space. The liver edge was palpable $2 \mathrm{~cm}$ below the right costal margin. The electrocardiogram showed sinus rhythm, right axis deviation, and right ventricular hypertrophy. The chest radiograph showed moderate cardiomegaly, pulmonary plethora, and a narrow vascular pedicle. The cross sectional echocardiogram was consistent with transposition of the great arteries with a ventricular septal defect.

^Present address: Dr Shakeel A Qureshi, Department of Paediatric Cardiology, Royal Liverpool Children's Hospital, Myrtle Street, Liverpool.

Requests for reprints to Dr Shakeel Ahmed Qureshi, Department of Paediatric Cardiology, Royal Liverpool Children's Hospital, Myrtle Street, Liverpool L7 7DG.

\section{CARDIAC CATHETERISATION}

Table 1 shows data on haemodynamic function. Angiocardiography confirmed complete transposition of the great arteries, ventricular septal defect, and ductus arteriosus. An aortogram showed filling of the pulmonary artery via the ductus arteriosus. There was definite but mild pulmonary regurgitation. There was considerable clinical improvement after a balloon atrial septostomy.

When the patient was eight months old a Senning procedure was performed, the ventricular septal defect was closed with a Dacron patch, and the ductus was ligated.

Postoperatively she had a persistent grade $3 / 6$ systolic murmur at the left sternal edge with residual cardiomegaly and pulmonary plethora on the chest radiograph. A first-pass radionuclide angiogram suggested a left to right shunt of $2 \cdot 2: 1$

\section{REPEAT CARDIAC CATHETERISATION}

Table 2 shows data on haemodynamic function. Angiocardiography (left ventricle and aorta) showed no residual ventricular septal defect but there was a

Table 1 Data on haemodynamic function before operation

\begin{tabular}{lll}
\hline Site & Pressure $(\mathrm{mm} \mathrm{Hg})$ & Saturation $(\%)$ \\
\hline SVC & - & 28 \\
IVC & - & 43 \\
MRA & Mean 3 & 37 \\
RV & Systolic 90 & - \\
& End diastolic 9 & - \\
Aorta & $90 / 40$ (mean 60) & 57 \\
LA & Mean 6 96 & 96 \\
LV & Systolic 90 & 87
\end{tabular}

SVC, superior vena cava; IVC, inferior vena cava; MRA, mid right atrium; RV, right ventricle; LA, left atrium; LV, left ventricle. 
Table 2 Data on haemodynamic function after operation

\begin{tabular}{lll}
\hline Site & Pressure $(\mathrm{mm} \mathrm{Hg})$ & Saturation (\%) \\
\hline SVC & Mean 8 & 49 \\
IVC & Mean 7 & 55 \\
SVA & Mean 7 & 58 \\
LV & Systolic 45 & 58 \\
& End diastolic 7 & \\
PA & 45/25 (mean 32) & 88 \\
PVA & Mean 10 & 98 \\
RV & Systolic 80 & 98 \\
& End diastolic 10 & 98 \\
Aorta & $75 / 35$ (mean 50) & 98 \\
\hline
\end{tabular}

See table 1 for abbreviations.

SVA, systemic venous atrium; PA, pulmonary artery; PVA, pulmonary venous atrium.

moderate sized ductus arteriosus through which an enlarged pulmonary artery became opacified. There was still some evidence of mild pulmonary regurgitation.

The ductus of $5 \mathrm{~mm}$ diameter was ligated through a left lateral thoracotomy and the child made a satisfactory recovery and is now symptom free.

\section{Discussion}

This patient initially had pulmonary regurgitation in the presence of severe pulmonary hypertension. Pulmonary regurgitation persisted after the Senning operation although pulmonary artery and left ventricular systolic pressures were greatly reduced. Because there was no discernible change in its severity, it is probable that the pulmonary regurgitation was caused by abnormal pulmonary valve structure. The abnormality must be a subtle one because neither the echocardiographic nor the angiographic appearances of the pulmonary valve were abnormal. Doppler ultrasonography was unhelpful in this case because the narrowness of the left ventricular outflow prevented correct positioning of the Doppler sample volume.

In the setting of venous redirection pulmonary regurgitation is of unknown but probably little haemodynamic importance. When an arterial switch is contemplated such incompetence of the valve, which is destined to support the systemic arterial pressures, may have a profound effect on the long term outcome.

Regurgitation of the aortic (previously pulmonary) valve has been reported in up to $20 \%$ of survivors after the arterial switch. ${ }^{1-3}$ Castaneda et al reported trivial aortic regurgitation in $9 \%$ of the patients after a primary arterial switch in the neonatal period. ${ }^{4}$ In another smaller series Quinones et al found trivial aortic regurgitation after operation in one out of nine patients who had undergone a primary arterial switch compared with four out of four patients who had had previous pulmonary
Qureshi, Ettedgui, fones

artery banding. ${ }^{5}$ This suggests that dilatation of the $e^{\complement}$ pulmonary artery proximal to the band is a possible explanation for the aortic regurgitation. Thus ito appears that aortic regurgitation occurs less fre- $\overline{0}$ quently after primary arterial switch in the neonatale period than after a two-stage switch. Nevertheless, it $\Phi$ is still found in the neonatal group and this raises the possibility that it may have been present before op- ${ }^{\infty}$ eration. This finding is present despite the fact that. the pulmonary valve in transposition of the great $\vec{\omega}$ arteries has the gross appearance of a normal aortic valve with normal attachment to the subaortic curtain and the fibrous skeleton of the heart. ${ }^{3}$ In patientsur undergoing more than one reinvestigation after $N$ operation, progression of aortic regurgitation has not $\frac{\vec{\sigma}}{\oplus}$ been noted. 367

The cause of the aortic regurgitation has been 9 ascribed to the operative technique. The circumfe- -

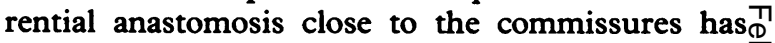
been incriminated together with, or as an alternative, the technique of coronary orifice reimplantation. This implies that aortic regurgitation after the arterial switch is in theory preventable, but this case ${ }_{\infty}^{\circ}$ casts doubt on the possibility of prevention.

It is pertinent to ask whether pulmonary regurgitation can be diagnosed in transposition of the great arteries. In our case diagnosis by angiography was possible only because the pulmonary artery was opacified retrogradely via the ductus arteriosus. $I_{\Omega} \stackrel{\varnothing}{\AA}$ the absence of a ductus pulmonary regurgitation $\overrightarrow{\vec{F}}$ cannot be demonstrated angiographically. The value 3 of Doppler ultrasonography in this setting has not? yet been defined. In some patients pulmonary? regurgitation is difficult to assess because of the narrowness of the left ventricular outflow tract. Examination by additional colour Doppler, however, is an attractive possibility and this technique may help to show whether, in general, pulmonary regurgitation in transposition of the great arteries is present before, produced during, or appears after operation.

\section{References}

1 Yacoub $\mathrm{MH}$, Bernhard A, Lange $\mathrm{P}$, et al. Clinical and haemodynamic results of the two-stage anatomic correction of simple transposition of the great arteries. Circulation 1980;62:190-6.

2 Williams WG, Trusler GA, Freedom RM, Olley PM, Duncan WJ, Rowe RD. Results of arterial repair of transposition: the Toronto experience. Pediatr Cardiol 1983;4:99-104.

3 Yacoub MH, Kakichara R, Arensman FW, Radley- $\frac{\mathbb{D}}{\mathbb{1}}$ Smith R. Current status of arterial switch operation 2 for the transposition of the great arteries. Nippon Kyobu Geka Zasshi 1983;31:623-33. 
4 Castaneda AR, Norwood WI, Hougen T, Jonas RA, Mayer JE Jr. Primary anatomic repair of transposition of the great arteries with intact ventricular septum in the neonate. In: Doyle EF, Engle MA, Gersony WM, Rashkind WJ, Talner NS, eds. Pediatric cardiology. New York: Springer-Verlag, 1986:621-3.

5 Quinones JA, Duffy CE, Gidding SS, et al. Twodimensional and Doppler echocardiographic assessment of anatomic correction for d-transposition of the great arteries. In: Doyle EF, Engle MA, Gersony WM, Rashkind WJ, Talner NS, eds. Pediatric cardiology. New York: Springer-Verlag, 1986:183-6.

6 Yacoub MH, Radley-Smith R. Venous versus arterial switch for the repair of transposition of the great arteries: a review. Pediatr Cardiol 1983;4:151-8.

7 Bernhard A, Yacoub MH, Regensburger D, et al. Further experience with the two-stage anatomic correction of simple transposition of the great arteries. Thorac Cardiovasc Surg 1981;29:138-42. 